\title{
Dynamics of phenolic compounds in leaves of Fragaria ananassa Duch. after treatment with different forms of chitosan
}

\author{
OLEKSANDR V. SUBIN ${ }^{1 *}$, ARTUR F. LIKHANOV ${ }^{1}$, OLEKSANDR V. SEREDA ${ }^{2}$, \\ ANDRII A. KLYUVADENKo ${ }^{1}$, MAKSYM D. MELNYCHUK ${ }^{3}$ \\ ${ }^{1}$ National University of Life and Environmental Sciences of Ukraine, Kyiv, Ukraine \\ ${ }^{2}$ China-Ukraine Life Sciences Research Institute, Zhuji, Zhejiang, People's Republic of China \\ ${ }^{3}$ National Academy of Agrarian Sciences of Ukraine, Kyiv Ukraine
}

\begin{abstract}
The article considers the effect of chitosans of different origin, molecular weight, and degree of deacetylation on the dynamics of phenolic substances in the leaves of Fragaria ananassa Duch. These substances potentially act as agents in plant responses to biotic stresses. We showed that the daily variations in individual phenolic compounds are most pronounced in the group of ellagitannins and kaempferol-3-b-D-[6-O-(E)-coumaroyl]-glucopyranoside. The most stable indicators were concentrations of kaempferol glycoside and ellagic acid pentoside. The strongest plant response to leaf treatment with low- and high-molecular-weight chitosans was a significant increase in the concentration of hexahydroxydiphenyl (HHDP)-glucose in leaves, peaking at $12 \mathrm{~h}$ after treatment. Treatment of $F$. ananassa with various forms of chitosans resulted in different concentrations of the basic phenolic substances. In particular, the plant response to a single treatment with $0.4 \%$ low-molecular-weight chitosan (LMC) was accompanied by a significant decrease in the ellagic acid concentration, after a slight increase in the first hour after treatment. The opposite effect was observed in plants after treatment with high-molecular-weight chitosan (HMC). We also determined the daily dynamics for the quantitative and qualitative composition of phenolic compounds in the control group of plants. By using the Biplot analysis, we showed a clear difference between phenol concentrations in the evening $(0,24$, and $48 \mathrm{~h})$ and in the morning $(12 \mathrm{~h})$. The strongest difference was an increase in the concentration of HHDP-glucose, galloylquinic acid, ellagic acid pentoside, kaempferol glycoside, and ellagic acid in leaves in the morning, followed by a decrease in the evening and nighttime, due to the physiological reactions of plants to external abiotic and biotic factors.
\end{abstract}

Key words: chitosan, HPLC, Fragaria ananassa, tannins, response reactions

\section{Introduction}

Plants are able to recognize pathogens and respond to them by activating a number of defensive reactions (Dmitriev, 2003). Plant resistance to pathogens is based on a complex network of constitutive and inducible protective barriers controlled by many genes (Smirnova et al., 2015). The effect of pathogen attack causes significant changes in plant metabolism. One of the characteristic cell reactions to infection is the so-called respiratory burst, the formation of reactive oxygen species (ROS) (Minibayeva and Gordon, 2003, Daudi et al., 2012, Del Rio and Lopes-Huertas, 2016, Leister, 2017,
Waszczak et al., 2018). The rapid production of ROS associated with the respiratory burst is one of the earliest responses of plant cells, preceded by the formation of elicitors, which are chemical signaling molecules. Elicitors play the role of primary signals and trigger the processes of induction and regulation of phytoimmunity (Hahn, 1996). As a rule, elicitors induce the formation of phytoalexins; pathogenesis-related (PR) proteins; proteinase inhibitors; reactive oxygen and nitrogen forms; and cell wall thickening with lignin, callose, and glycoproteins with a high concentration of hydroxyproline (Ozeretskovskaya et al., 2002). The biogenic nonspecific

* Corresponding author: National University of Life and Environmental Sciences of Ukraine, Kyiv, Ukraine; e-mail: subin.oleksandr@gmail.com 
elicitors include polysaccharides, proteins, polypeptides, glycoproteins, lipid compounds, and other substances (Dmitriev, 2002; Tyuterev, 2002).

Among the best-known polysaccharide elicitors are oligosaccharide fragments of the fungal cell wall, such as oligomers of chitin, chitosan, and $\beta$-1,3-glucan, as well as oligogalacturonides, which are pectin fragments of the plant cell wall (Sokolov, 2014). The biological activity of chitooligosaccharides depends on their structure. Thus, chitosan derivatives regulate the plant defense system with a wide range of effects (Katiyar et al., 2014). For instance, several studies have demonstrated that the key parameters of chitosan biological activity are molecular weight and the degree of deacetylation (Kulikov et al., 2006, El Hadrami et al., 2010, Povero et al., 2011, Tyuterev, 2015, Popova et al., 2017, Lopez-Moya et al., 2019).

The low-molecular-weight forms of chitosan can penetrate cells and induce reprogramming of metabolic processes. High-molecular-weight chitosan forms a film on the surface of infected plant tissues and prevents further spreading of pathogens (Kulikov and Varlamov, 2008).

It has been reported that chitosan treatment induces the expression of important genes involved in the metabolism of phenylpropanoids, such as caffeoyl CoA O-methyltransferases, which have been implicated in lignin biosynthesis in citrus plants (Coqueiro et al., 2015). The participation of chitosan in the metabolism of phenylpropanoids has also been observed in tomato plants ( $\mathrm{Co}-$ queiro et al., 2011). In Vitis vinifera L. plants, an increase in the amount of stilbenes from 1.6 times (resveratrol) up to 3.8 times (piceid) was observed after treatment with chitosan. Furthermore, when induced by chitosan, the pentacyclic triterpenoids ursolate, oleanoate, and betulinate increased by $1.25,1.47$, and 3.68 times in treated grape bunches (Lucini et al., 2018). Another research showed that superoxide dismutase (SOD) and phenylalanine ammonia-lyase (PAL) were overexpressed in chitosan-treated grapes (Bavaresco et al., 2017). Previous studies have demonstrated differences in the physiological reactions of the plants Nicotiana tabacum and Fragaria ananassa to treatment with chitosans of different biological origin, molecular weight, and degree of deacetylation (Subin et al., 2018). It was also noted that this biopolymer acts as a potent inducer of phytoalexin synthesis and accumulation (Köhle et al., 1984), and triggers the formation of callose (Benhamou and Nicole, 1999) in the processes of lignification and in the production of proteinase inhibitors (Hirano et al., 1999) in various pathosystems (El Hadrami et al., 2010).

The present study aimed to investigate the specificity of dynamics of phenolic compounds in Fragaria ananassa Duch. plants after the treatment with chitosan with different molecular weights, degrees of deacetylation, and origins (from fungi and crustaceans).

\section{Materials and methods}

\section{Chitosan characterization}

The first form of fungal chitosan (low molecular weight $[\mathrm{LMC}]$ ) was obtained by the fermentative hydrolysis of basidiomycete sporocarps in our laboratory by the procedure adapted from Rane and Hoover (1993). The second form (high molecular weight [HMC]) was commercial crustacean chitosan (Sigma-Aldrich).

\section{Determination of the degree of deacetylation of chitosan forms}

The deacetylation of chitosan was performed by titration with $0.1 \mathrm{M} \mathrm{NaOH}$. First, the acetyl groups in chitosan were hydrolyzed with a strong alkali $(40 \% \mathrm{NaOH})$, and the salt was converted to acetate, followed by evaporation as an azeotrope with water and then titrated with $0.1 \mathrm{M} \mathrm{NaOH}$. Thus, the content of acetyl (in percentages) was determined from the following equation:

$$
D A=2.03 \cdot \frac{\left(V_{2}-V_{1}\right)}{m+0.0042 \times\left(V_{2}-V_{1}\right)}
$$

where $m$ is sample mass; $V_{1}$ and $V_{2}$ are volumes of $0.1 \mathrm{M} \mathrm{NaOH}$ titrating solution at the inflection points of the titration curve; 0.0042 is the coefficient of the difference of molecular masses of chitin and chitosan monomers; and 2.03 is the molecular mass coefficient of the chitin monomer.

\section{Determination of the kinematic viscosity of chitosan forms}

A capillary viscometer (VPZh- 1 ) with $0.86 \mathrm{~mm}$ diameter was used to measure the viscosity of fungal and crustacean chitosans. The chitosan solution was prepared in $1 \%$ acetic acid at $1 \%$ concentration on a moisturefree basis. The measurements were made in triplicate for each sample, and the values were reported in centipoise units $(\mathrm{cP})$. 
The liquid kinematic viscosity was determined by the formula:

$$
V=\frac{g}{9.807} \cdot T \times K
$$

where $K$ is viscometer constant $(0.03169)$; $V$ is kinematic viscosity of liquid $\left(\mathrm{mm}^{2} / \mathrm{s}\right) ; T$ is time of liquid leakage (s); $g$ is the acceleration of free fall at the place of measurement $\left(9.81 \mathrm{~m} / \mathrm{s}^{2}\right)$.

\section{Plant material and treatment with chitosan solutions}

Fragaria ananassa Duch. plants (variety Alina) were used in the experiments. Microclonally propagated plants were adapted to in vivo conditions. The microplants were transferred to coconut: perlite $(3: 1)$ mixture and were grown for 2 weeks at a constant temperature of $+25^{\circ} \mathrm{C}$, photoperiod of $16 \mathrm{~h}$, and $100 \%$ humidity. After adaptation, the plants were grown on a special commercial coconut substrate (ViviPak ${ }^{\mathrm{TM}}$ ) in a culture laboratory at a constant temperature of $+25^{\circ} \mathrm{C}$ and photoperiod of $16 \mathrm{~h}$.

The $0.4 \%$ solution of fungal and crustacean chitosans were dissolved in $0.05 \mathrm{~N}$ hydrochloric acid, and the $\mathrm{pH}$ was then adjusted to 5.6 with $\mathrm{NaOH}$. Distilled water was used as control.

The leaf samples were collected before spraying (controls) and after 1, 12, 24, and $48 \mathrm{~h}$. Each leaf sample was ground to a fine powder in a mortar chilled with liquid nitrogen, and $100 \mathrm{mg}$ of the grounded sample was used for extraction with $3 \mathrm{ml}$ methanol for $2 \mathrm{~h}(\mathrm{w} / \mathrm{v}$ $1 / 30$ ). The extracts were centrifuged for $10 \mathrm{~min}$ at $5000 \mathrm{~g}$. The supernatant was then transferred to sterile flacons and stored at $-20^{\circ} \mathrm{C}$. The number of repetitions was $n=4$.

\section{HPLC analysis of methanol extracts}

The samples were analyzed with the HPLC system (Agilent 1260 series, Waldbronn, Germany) equipped with a diode array absorbance detector (DAD). A Zorbax SB-C18 column, $250 \times 4.6 \mathrm{~mm}, 5 \mu \mathrm{m}$ of i.d. (Agilent, USA) was used. The mobile phase consisted of acetonitrile (A) and phosphoric acid diluted in water $(0.5: 99.5 \mathrm{v} / \mathrm{v})(\mathrm{B})$ at a flow rate of $1 \mathrm{ml} / \mathrm{min}$. Phenolic compounds were separated in the following gradient of $\mathrm{A}$ in $\mathrm{B}(\% \mathrm{v} / \mathrm{v}): 0-5 \mathrm{~min}, 15 \% \mathrm{~A} ; 5-25 \mathrm{~min}, 15-35 \% \mathrm{~A}$; 25-35 min, 35\% A. UV spectra were recorded between 200 and $450 \mathrm{~nm}$, and the UV trace was measured at
$254 \mathrm{~nm}$. The column was maintained at $25^{\circ} \mathrm{C}$. The processing and visualization of chromatographic data (including absorption spectra) were performed using Agilent Chem Station and Corel Draw X3 software. Ellagic acid and rutoside were used as external standard for the quantification of tannins and flavonoids, respectively.

\section{Statistical analysis}

The obtained results were presented as mean values. The data were analyzed in Statistica 7 (StatSoft Inc., USA, 2004). The significance of differences between the values $(P<0.05)$ was determined by the analysis of variance (ANOVA) method and the Principal Component Analysis (PCA) in the XLSTAT (Addinsoft Inc., USA, 2010). The data were compared using Tukey's test.

\section{Results}

The development of plant response reactions is an important indicator of their susceptibility to pathogens. The response rate determines the survival strategy of the plant organism. In most cases, the protective mechanisms are not limited to the primary response and include changes at the transcriptome, cellular, and physiological levels (Atkinson and Urwin, 2012). The most significant response reaction to stress factor or action of elicitor is the oxidation of phenolic compounds and the synthesis of phytoalexins (Volynets, 2013). Our previous study showed that the synthesis of phenolic compounds in Fragaria ananassa plants is quite mobile and sensitive to external factors (Subin et al., 2018). It is also known that a significant difference exist in the synthesis of phenolic compounds in different plant species (Babenko et al., 2019). Because the resistance of plants to external factors in $F$. ananassa is related to the synthesis of phenolic compounds, the difference in this component of secondary metabolism also determines the peculiarities of their adaptation.

\section{Determination of the physicochemical properties of chitosans}

In the first stage of our research, physicochemical properties such as the degree of deacetylation, kinematic viscosity, and molecular weight were determined for fungal and crustacean chitosans. The degree of deacetylation for fungal and crustacean chitosan was 80.39 and $90.69 \%$, respectively. For fungal chitosan, the value 


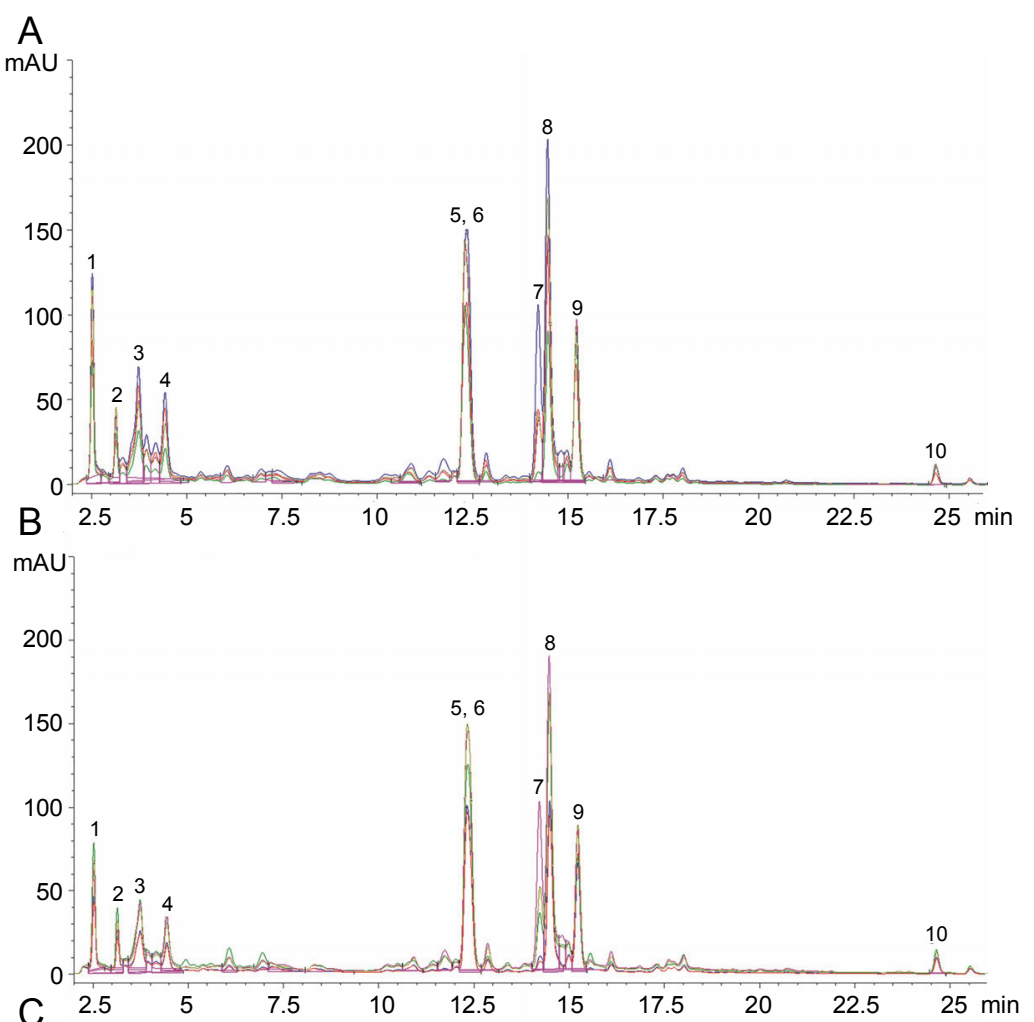

Fig. 1. Combined (0-48 hours) HPLC chromatograms of $F$. ananassa leaves: A) control; B) LMC treatment; C) HMC treatment; 1 - HHDP-glucose, 2 - galloylquinic acid, 3 - ellagitannin, 4 - ellagitannin, 5, 6 - ellagic acid pentoside and kaempferol glycoside, 7 - ellagitannin, 8 - ellagic acid, 9 - kaempferol glycoside, 10 - tiliroside

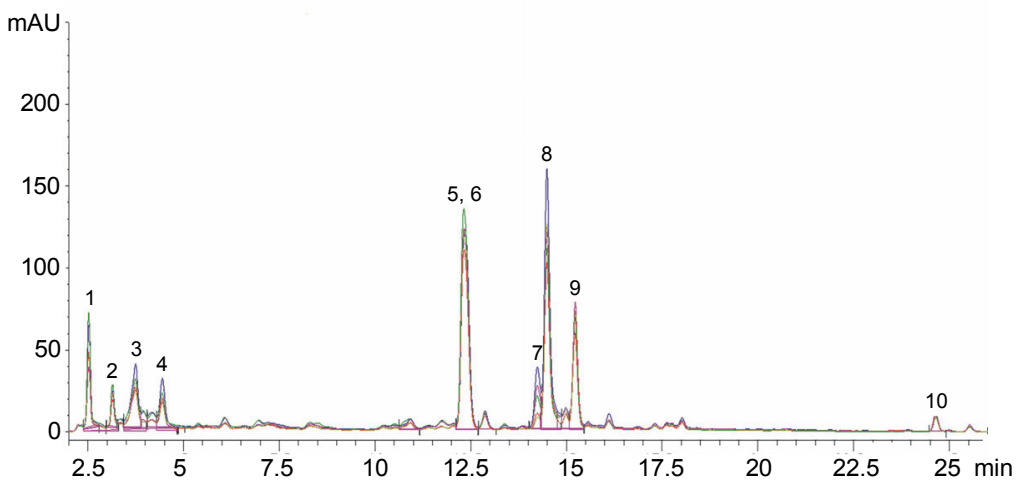

of kinematic viscosity was $111 \mathrm{cP}$, indicating it to be LMC. For crustacean chitosan, the value of kinematic viscosity was $3003 \mathrm{cP}$, indicating it to be HMC.

\section{HPLC analysis of the phenolic compound of $F$. ananassa}

The HPLC study of methanol extracts obtained from the leaves of $F$. ananassa revealed the presence of 10 major components, mainly hydrolyzed tannins (derivatives of gallic and ellagic acids) and flavonoids, among other phenolic substances (Fig. 1). Peaks 3-7 and 9 were assigned as ellagitannins and kaempferol glycosides based on the characteristic UV spectra. Peak 8 was identical to the peak on the chromatograms of the ellagic acid standard. In accordance with the characteristic UV spectra and retention time, compared with the literature data on the study of strawberry under similar chromatographic conditions and with MS identification (Hanhineva et al., 2008, 2009), peaks 1, 2, and 10 were correlated with glucose hexahydroxydiphenyl (HHDP), galloylquinic acid, and tiliroside (kaempferol-3-b-D-[6-O-(E)coumaroyl]-glucopyranoside), respectively. It should be noted that the component composition of phenols in the leaves of $F$. ananassa was stable in each treatment variant (Fig. 1).

The concentration of ellagic acid in the leaves of $F$. ananassa significantly increased at $1 \mathrm{~h}$ after spraying with $\mathrm{LMC}$ (to $0.53 \mathrm{mg} / \mathrm{ml}$ ) and HMC (to $0.48 \mathrm{mg} / \mathrm{ml}$ ) (Table 1); however, its concentration slightly decreased after $12 \mathrm{~h}$ to $0.30 \mathrm{mg} / \mathrm{ml}$ for LMC and to $0.45 \mathrm{mg} / \mathrm{ml}$ for HMC. In the leaves of the control plants, a smooth in- 
Table 1. The influence of low molecular weight (LMC) and high molecular weight (HMC) chitosans on the concentration of phenolic substances in $F$. ananassa leaves

\begin{tabular}{|c|c|c|c|c|c|c|c|c|c|c|c|}
\hline \multirow{3}{*}{ Treatment } & \multirow{3}{*}{$\begin{array}{c}\text { Time } \\
{[\mathrm{h}]}\end{array}$} & \multicolumn{10}{|c|}{ Concentration $[\mathrm{mg} / \mathrm{ml}]$} \\
\hline & & Peak 1 & Peak 2 & Peak 3 & Peak 4 & Peak 5, 6 & Peak 7 & Peak 8 & Peak 9 & Peak 10 & \multirow{2}{*}{ Total } \\
\hline & & $\mathrm{A}$ & B & $\mathrm{C}$ & $\mathrm{D}$ & $\mathrm{E}$ & $\mathrm{F}$ & G & $\mathrm{H}$ & I & \\
\hline \multirow{5}{*}{ Control } & 0 & $0.61 \pm 0.009^{b}$ & $0.03 \pm 0.001^{b}$ & $0.55 \pm 0.006^{\mathrm{b}}$ & $0.74 \pm 0.006^{b}$ & $0.23 \pm 0.003^{b}$ & $0.49 \pm 0.01$ & $0.25 \pm 0.003$ & $0.62 \pm 0.008^{\mathrm{b}}$ & 0.00 & $3.53 \pm 0.02^{b}$ \\
\hline & 1 & $0.91 \pm 0.007^{b}$ & $0.07 \pm 0.001^{b}$ & $0.66 \pm 0.009^{\mathrm{a}}$ & $0.0 \pm 0.001^{b}$ & $0.35 \pm 0.005^{\mathrm{a}}$ & $0.01 \pm 0.001$ & $0.36 \pm 0.005^{b}$ & $0.78 \pm 0.006^{b}$ & 0.00 & $3.15 \pm 0.01^{b}$ \\
\hline & 12 & $0.95 \pm 0.01$ & $0.07 \pm 0.001^{b}$ & $0.01 \pm 0.001$ & $0.06 \pm 0.001^{b}$ & $0.37 \pm 0.004^{a}$ & 0.00 & $0.57 \pm 0.006^{b}$ & $0.68 \pm 0.01^{b}$ & $0.21 \pm 0.004$ & $2.93 \pm 0.03^{b}$ \\
\hline & 24 & $0.80 \pm 0.02^{b}$ & $0.06 \pm 0.002^{b}$ & $0.87 \pm 0.007^{b}$ & $0.02 \pm 0.001^{\mathrm{a}}$ & $0.26 \pm 0.003^{b}$ & $0.02 \pm 0.001^{b}$ & $0.34 \pm 0.004^{b}$ & $0.58 \pm 0.005^{b}$ & $0.22 \pm 0.004$ & $3.17 \pm 0.03^{b}$ \\
\hline & 48 & $0.60 \pm 0.01^{\mathrm{b}}$ & $0.03 \pm 0.001^{b}$ & $0.83 \pm 0.008^{b}$ & $0.02 \pm 0.001^{\mathrm{a}}$ & $0.26 \pm 0.004^{\mathrm{b}}$ & $0.02 \pm 0.001$ & $0.25 \pm 0.004^{\mathrm{b}}$ & $0.59 \pm 0.007^{\mathrm{b}}$ & 0.00 & $2.61 \pm 0.01^{\mathrm{b}}$ \\
\hline \multirow{5}{*}{ LMC } & 0 & $0.03 \pm 0.001$ & $0.16 \pm 0.003^{b}$ & $0.03 \pm 0.001$ & $0.09 \pm 0.002^{b}$ & $0.38 \pm 0.005^{b}$ & 0.00 & $0.05 \pm 0.001$ & $0.88 \pm 0.008^{b}$ & 0.00 & $1.62 \pm 0.01$ \\
\hline & 1 & $0.02 \pm 0.001^{\mathrm{b}}$ & $0.12 \pm 0.002^{b}$ & $0.02 \pm 0.001$ & $0.10 \pm 0.002^{b}$ & $0.40 \pm 0.005^{a}$ & 0.00 & $0.53 \pm 0.007^{b}$ & $0.78 \pm 0.003$ & 0.00 & $1.97 \pm 0.006^{\mathrm{b}}$ \\
\hline & 12 & $0.85 \pm 0.02$ & $0.03 \pm 0.001^{b}$ & $0.80 \pm 0.01$ & $0.01 \pm 0.001^{b}$ & $0.29 \pm 0.002$ & $0.02 \pm 0.001$ & $0.30 \pm 0.003^{b}$ & $0.78 \pm 0.002$ & $0.15 \pm 0.004$ & $3.23 \pm 0.02^{\mathrm{b}}$ \\
\hline & 24 & $0.02 \pm 0.001^{b}$ & $0.11 \pm 0.003^{b}$ & $0.97 \pm 0.004^{b}$ & $0.02 \pm 0.001$ & $0.25 \pm 0.006$ & $0.50 \pm 0.01^{b}$ & $0.26 \pm 0.005^{\mathrm{b}}$ & $0.64 \pm 0.01^{b}$ & 0.00 & $2.78 \pm 0.02^{b}$ \\
\hline & 48 & $0.95 \pm 0.02^{b}$ & $0.04 \pm 0.001$ & $0.88 \pm 0.008^{b}$ & $0.02 \pm 0.001$ & $0.24 \pm 0.005^{b}$ & $0.99 \pm 0.007$ & $0.27 \pm 0.005$ & $0.63 \pm 0.004^{\mathrm{b}}$ & \begin{tabular}{|l|l|}
$0.19 \pm 0.004$ \\
\end{tabular} & $4.22 \pm 0.01^{b}$ \\
\hline \multirow{5}{*}{$\mathrm{HMC}$} & 0 & $0.02 \pm 0.001^{b}$ & $0.12 \pm 0.002^{b}$ & $0.01 \pm 0.0002^{b}$ & $0.03 \pm 0.001^{\mathrm{b}}$ & $0.30 \pm 0.004^{\mathrm{b}}$ & $0.02 \pm 0.001$ & $0.30 \pm 0.004$ & $0.77 \pm 0.007^{b}$ & 0.00 & $1.57 \pm 0.006^{\mathrm{b}}$ \\
\hline & 1 & $0.03 \pm 0.001$ & $0.21 \pm 0.003^{b}$ & $0.02 \pm 0.001^{a}$ & $0.07 \pm 0.002$ & $0.35 \pm 0.005$ & 0.00 & $0.48 \pm 0.004^{b}$ & $0.94 \pm 0.006^{b}$ & 0.00 & $2.1 \pm 0.007^{\mathrm{b}}$ \\
\hline & 12 & $0.95 \pm 0.008$ & $0.07 \pm 0.001$ & $0.01 \pm 0.001$ & $0.04 \pm 0.001$ & $0.28 \pm 0.007^{\mathrm{a}}$ & $0.06 \pm 0.001$ & $0.45 \pm 0.007^{b}$ & $0.79 \pm 0.006^{\mathrm{b}}$ & 0.00 & $2.65 \pm 0.009^{b}$ \\
\hline & 24 & $0.04 \pm 0.001$ & $0.16 \pm 0.003^{b}$ & $0.02 \pm 0.001^{b}$ & $0.09 \pm 0.003^{a}$ & $0.31 \pm 0.005^{b}$ & $0.04 \pm 0.001$ & $0.39 \pm 0.009^{b}$ & $0.71 \pm 0.009^{b}$ & $0.05 \pm 0.001$ & $1.82 \pm 0.008^{b}$ \\
\hline & 48 & $0.02 \pm 0.001^{b}$ & $0.08 \pm 0.002^{b}$ & $0.01 \pm 0.001^{\mathrm{b}}$ & $0.06 \pm 0.001^{\mathrm{a}}$ & $0.31 \pm 0.005^{\mathrm{b}}$ & 0.00 & $0.40 \pm 0.007^{\mathrm{b}}$ & $0.78 \pm 0.006^{\mathrm{b}}$ & 0.00 & $1.66 \pm 0.01^{\mathrm{b}}$ \\
\hline
\end{tabular}

A - HHDP-glucose, B - galloylquinic acid, C - ellagitannin, D - ellagitannin, E - ellagic acid pentoside and kaempferol glycoside, F - ellagitannin, G - ellagic acid, H - kaempferol glycoside, I - tiliroside; maximums are marked bold; note: significant differences compared to the control was assessed by one-way ANOVA; a significant differences at $P<0.05, \mathrm{~b}-$ significant differences at $P<0.01$ 
A

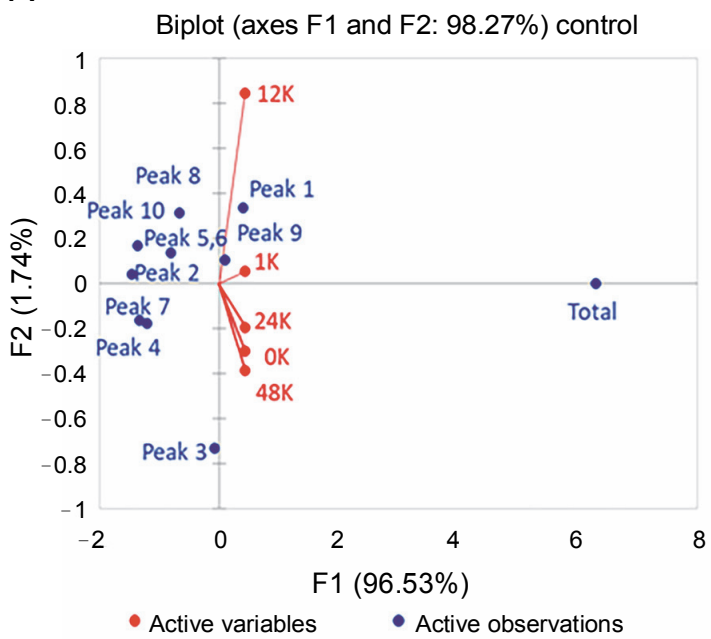

C

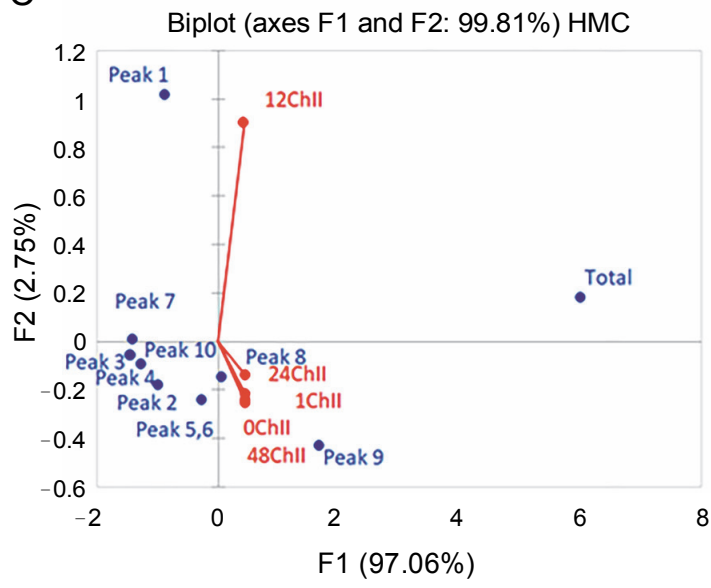

- Active variables $\quad$ Active observations
B

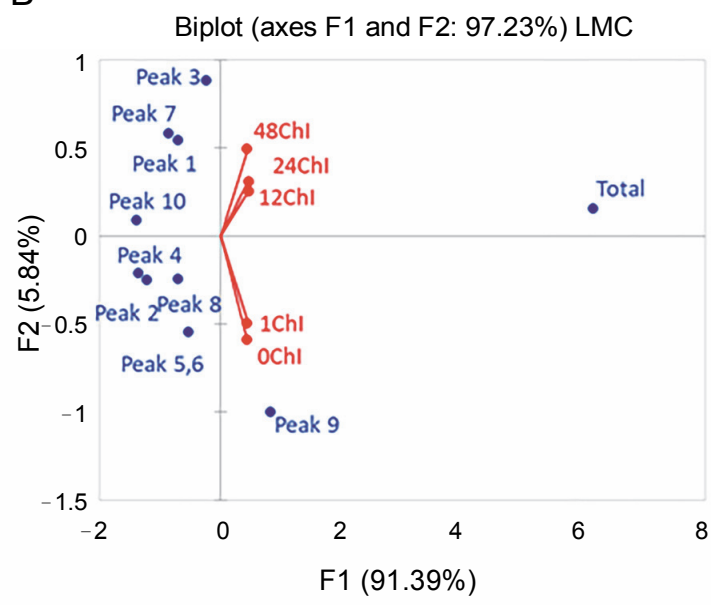

- Active variables • Active observations

D

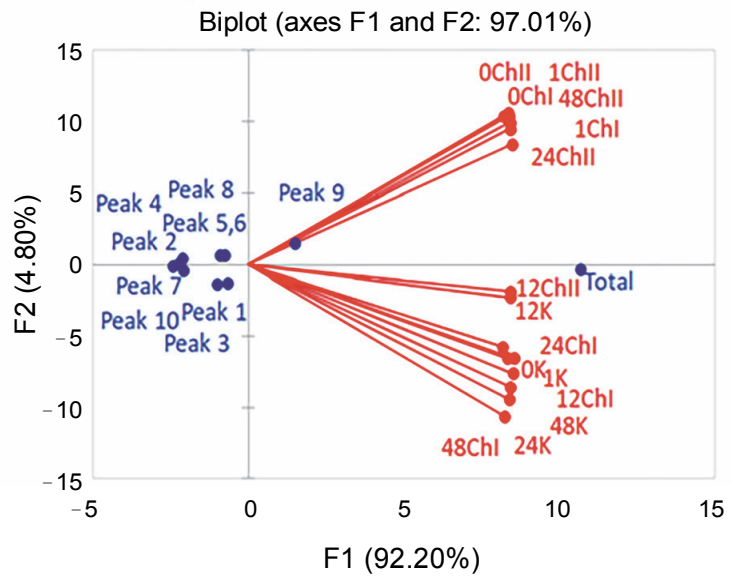

- Active variables - Active observations

Fig. 2. Biplot principal components analysis of the concentrations of phenolic substances in $F$. ananassa leaves: A) control; B) low molecular weight chitosan; C) high molecular weight chitosan, D) combined data (K - control, ChI - LMC, ChII - HMC)

Table 2. Principal component analysis (PCA) of the concentrations of phenolic substances in $F$. ananassa leaves

\begin{tabular}{|c|c|c|c|c|c|c|c|}
\hline \multirow{3}{*}{ Number } & \multirow{3}{*}{ Compound } & \multicolumn{2}{|c|}{ Control } & \multicolumn{2}{|c|}{ LMC } & \multicolumn{2}{|c|}{ HMC } \\
\hline & & \multicolumn{6}{|c|}{ Factor scores } \\
\hline & & F1 & $\mathrm{F} 2$ & $\mathrm{~F} 1$ & F2 & F1 & $\mathrm{F} 2$ \\
\hline Peak 1 & HHDP-glucose & 0.426 & 0.334 & -0.701 & 0.545 & -0.888 & 1.017 \\
\hline Peak 2 & galloylquinic acid & -1.443 & 0.037 & -1.212 & -0.255 & -0.983 & -0.182 \\
\hline Peak 3 & ellagitannin & -0.056 & -0.738 & -0.226 & 0.886 & -1.439 & -0.056 \\
\hline Peak 4 & ellagitannin & -1.183 & -0.180 & -1.351 & -0.213 & -1.274 & -0.096 \\
\hline Peak 5, 6 & ellagic acid pentoside; kaempferol glycoside & -0.811 & 0.131 & -0.519 & -0.547 & -0.270 & -0.238 \\
\hline Peak 7 & ellagitannin & -1.328 & -0.166 & -0.866 & 0.584 & -1.423 & 0.004 \\
\hline Peak 8 & ellagic acid & -0.669 & 0.313 & -0.696 & -0.242 & 0.065 & -0.145 \\
\hline Peak 9 & kaempferol glycoside & 0.104 & 0.106 & 0.814 & -0.997 & 1.657 & -0.426 \\
\hline Peak 10 & $\begin{array}{l}\text { tiliroside; } \\
\text { kaempferol-3-b-D-[6-O-(E)-coumaroyl]-glucopyranoside }\end{array}$ & -1.355 & 0.167 & -1.390 & 0.083 & -1.455 & -0.060 \\
\hline Total & & 6.315 & -0.005 & 6.145 & 0.157 & 6.010 & 0.182 \\
\hline
\end{tabular}


crease in ellagic acid concentration was noted at night $(0.57 \mathrm{mg} / \mathrm{ml})$, followed by a decrease in the afternoon $(0.34 \mathrm{mg} / \mathrm{ml})$. Treatment of plants with chitosans caused an abrupt increase in the concentration of ellagic acid in the leaves (Table 1).

The concentration of individual components and the total concentration of phenols in $F$. ananassa leaves were quite variable. Thus, the variation coefficient of the total phenol concentration was $50.1 \%$, while the greatest ranges were found for HHDP-glucose (Peak 1 on chromatograms) and ellagitannins (Peaks 3, 4, and 7) (Table 1).

Our studies revealed the daily dynamics of the qualitative and quantitative composition of ellagitannins and flavonoids in strawberry leaves. The largest daily variations of individual phenolic compounds were registered in the group of ellagitannins (Peaks 3, 4, and 7) and kaempferol-3-b-D-[6-O-(E)-coumaroyl]-glucopyranoside (Peak 10). The most stable in the leaves of this variety was the concentration of kaempferol glycoside (Peaks 6 and 9) and ellagic acid pentoside (Peak 5) (Table 1).

When processing the complex of phenols using the principal component analysis, the first axis (F1) accounted for $96.53 \%$ of the total dispersion of the concentrations of individual phenolic compounds (Fig. 2). The greatest contribution to the total dispersion was made by galloylquinic acid, tiliroside, and ellagic acid pentoside. Ellagitannin (Peak 7) and ellagic acid had a slightly smaller value (Table 2). In the control group, the F1 axis separated the concentrations of the main individual phenolic compounds from their total concentration. The concentration of kaempferol glycoside in leaves was relatively stable (Table 1).

The second axis of the main components (F2) accounted for $1.74 \%$ of the total dispersion, where the highest value was for ellagitannin (Peak 3 ). In the group of studied phenolic substances, the total dispersion of 1 and 2 main components was $98.27 \%$. This enabled to apply the Biplot analysis (Fig. 2).

Regarding F1 and F2 axes, the grouping of concentrations by the sampling time indicated the daily dynamics of individual phenolic components. Thus, the $\mathrm{F} 2$ axis divided the phenol concentrations in the evening $(0,24$, and $48 \mathrm{~h})$ and morning $(12 \mathrm{~h})$. The concentrations of HHDP-glucose $(0.95 \mathrm{mg} / \mathrm{ml})$, galloylquinic acid $(0.07 \mathrm{mg} / \mathrm{ml})$, ellagic acid pentoside with kaempferol glycoside $(0.37 \mathrm{mg} / \mathrm{ml})$, and ellagic acid $(0.57 \mathrm{mg} / \mathrm{ml})$ in the leaves notably increased in the morning, followed by a decrease in the evening and at night (Table 1).
These daily dynamics of the concentrations of the phenolic compounds studied are described by the following logistic curve:

$$
f(y)=y_{0}+\frac{a}{x} \cdot \exp \left(-0.5\left(\frac{\ln \frac{x}{x_{0}}}{b}\right)^{2}\right)
$$

This mathematical model accurately describes the dynamics of the process; however, the expected increase in kaempferol and ellagic acid concentrations in the night needs experimental confirmation (Fig. 3).

In control plants, a close direct relationship between the concentrations of ellagic acid and HHDP-glucose and galloylquinic acid in the leaves was confirmed by the multiple correlation analysis (Pearson correlation coefficient $r=0.90$ ). An inverse correlation (Pearson correlation coefficient $r=-0.90$ ) was found between the concentrations of ellagic acid and ellagitannin (Peak 7). However, the concentration of the latter in leaf extracts was an order of magnitude smaller; hence, it is very difficult to consider such a relationship as significant and metabolically related. Thus, the observed physiological features confirm the daily fluctuations in the accumulation of phenolic substances in the vegetative and generative parts of the plants. It should also be noted that the daily dynamics in the concentration of phenolic substances may differ significantly in various plant species. It may also be affected by significant external stimuli on plants (Feduraev et al., 2019). This is confirmed by differences in the concentrations of individual phenolic components and their total concentration 2 days after the treatment with LMC and HMC (Table 1). The plants responded to a single treatment with $0.4 \% \mathrm{LMC}$ with a significant decrease in ellagic acid concentration, after a slight increase in the first hour after treatment (Fig. 4A). The opposite effect was observed in plants after their treatment with HMC (Fig. 4B).

The strongest plant response to leaf treatments with LMC and HMC was a significant increase in HHDPglucose concentration in the leaves. In both variants of plant treatment, the peak reached its maximum at $12 \mathrm{~h}$ (Fig. $4 \mathrm{C}$ and Fig. 4D). For both variants, this index was $0.95 \mathrm{mg} / \mathrm{ml}$. The dynamics of this process are described by the modified Gauss function: 

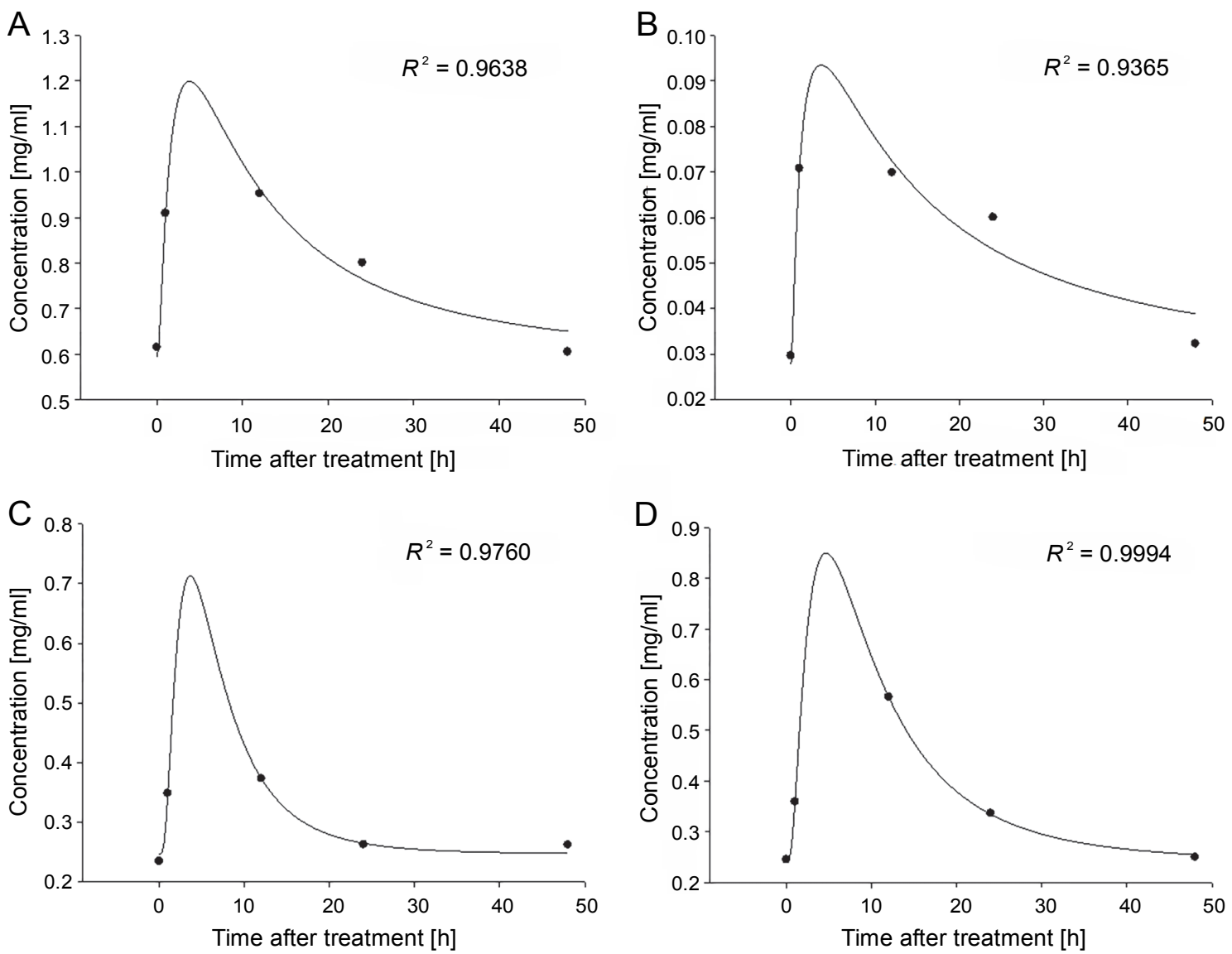

Fig. 3. Concentration dynamics of A) HHDP-glucose, B) galloylquinic acid, C) ellagic acid pentoside, kaempferol glycoside, and D) ellagic acid in $F$. ananassa leaves

$$
f(y)=a \cdot \exp \left[-0.5\left(\frac{x-x_{0}}{b}\right)^{c}\right]
$$

For LMC, the dynamics are described by:

$$
y=y_{0}+a \cdot \sin \left(\frac{2 \pi x}{b}+c\right)
$$

With a sharp increase in HHDP-glucose concentration in leaf tissues, not only the antioxidant but also the prooxidant potential of plants increased (Yordi et al., 2012, Kallio et al., 2013). This ensures the readiness of the plant body to counteract external negative factors.

\section{Discussion}

According to J.-P. Salminen (2011), the protective effectiveness of ellagitannins is higher than that of gallotannins, because ellagitannins can form o-quinones with strong electrophilic properties. In addition, because of the antifeedant activity of tannins based on protein, precipitation is enhanced by their pro-oxidant activity, especially under alkalescent conditions (Salminen et al., 2011).

Polygalloylglucoses are produced at the start of the synthesis of tannins in plant cells. They have a relatively low pro-oxidant potential. Further transformation of gallotannins into ellagitannins leads to an increase in the total pro-oxidant activity of the cells (Barbehenn et al., 2006). Quantitative changes in the concentration of strawberry ellagitannins in response to chitosans also implicate the activation of the corresponding enzyme systems. Ellagitannins in plant tissues undergo enzymatic hydrolysis (Klumpers et al., 1994). Ellagic acid is formed by the lactonization of hexaoxydiphenic acid, which is released during the hydrolysis of ellagitannins. An increase in the total pool of ellagic acid implicates an increase in the intensity of the oxidative processes in plant tissues (Schulenburg et al., 2016).

A phytopathogenic fungal infection leads to the accumulation of ellagic acid (EA) in plants (Zaprometov, 1993). Hence, a sharp jump in EA concentration after treatment 

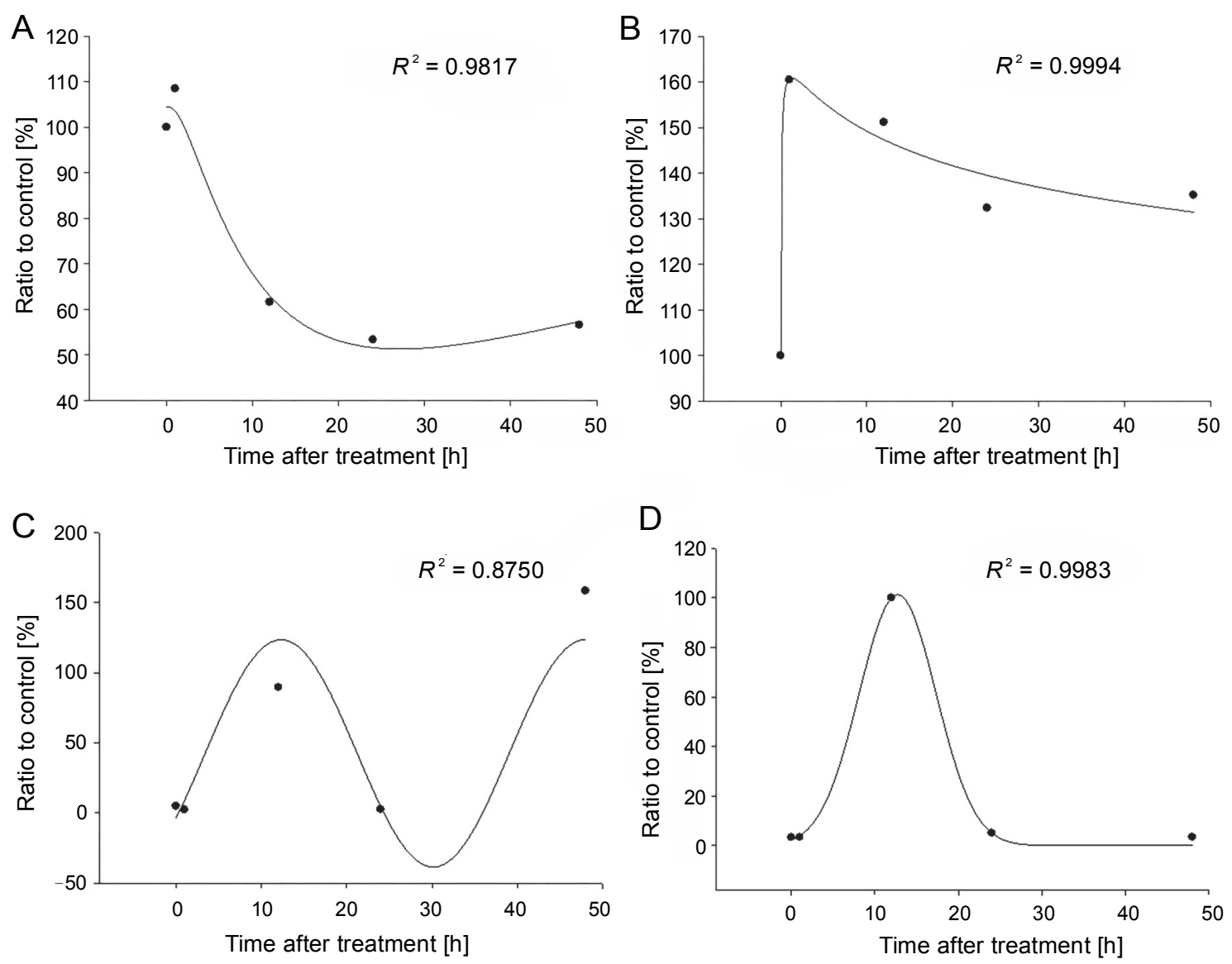

Fig. 4. Concentration dynamics of A, B) ellagic acid and C, D) HHDP-glucose in $F$. ananassa leaves after their treatment with $\mathrm{A}, \mathrm{C}$ ) low and B, D) high molecular weight chitosan

with HMC may indicate a manifestation of its elicitor activity with the activation of the corresponding hydrolases. The opposite effect (a sharp decrease in EA concentration) noted after the plants were treated with the fungal chitosan (LMC) was probably due to the lower mass of oligomers and a higher degree of their deacetylation.

The elicitor activity of chitosan significantly depends on the number of its acetyl groups (Popova et al., 2017). Chitin oligomers in wheat leaves increase peroxidase activity, chitosan increases peroxidase and phenylalanine-ammonia-lyase activity, and deacetylated chitosan accelerates the formation of lignin (Vander et al., 1998). Fully deacetylated oligomers induce chitinase activity in rice cells (Inui et al, 1997) and phenylalanine-ammonium and tyrosine-ammonia-lyase activity in soybean leaves (Khan et al., 2003). The rate of physiological responses in plants may also differ significantly. The activity of PR-1 and phenylalanine-ammonia-lyase increases in less than $24 \mathrm{~h}$ with the elicitor activation of NO synthase (Klessig et al., 2000). In our experiments, significant physiological responses to the effects of chitosans in strawberry leaves were recorded in the first $12 \mathrm{~h}$ after treatment. This fact indicates the importance of the molecular signals used in the experiment for the plant organism.

The physiological increase in the concentration of HHDP-glucose, galloylquinic, ellagic acid, and ellagic acid pentoside in the leaves at night might be due to the specifics of phenolic synthesis as well as the fact that a reducing temperature accompanied by a simultaneous increase in humidity at night creates favorable conditions for the growth of most pathogenic fungi. This, in turn, increases the risk of plant infections. The synthesis of phenolic substances allows for developing constitutional resistance, which includes mechanical strength and the ability of plant cell wall to counteract negative environmental factors (Shittu et al., 2019). Polymerized ellagitannins are mostly medium and low polar compounds. Some of them covalently bind with the components of plant cell walls (Helm et al., 1997). The peroxidase sy- 
stem promotes the increasing content of polyphenolic components in the cell wall. This is accompanied by the activation of phenylpropanoid metabolism enzymes involved in the formation of hydroxycinnamic alcohols and other components of lignin, which are necessary for the resistance of the plant organism (Le Roy et al., 2016).

\section{Conclusions}

Based on the results of the present study, the daily dynamics of the flavonoids, hydrolyzed tannins, and derivatives of gallic and ellagic acids were confirmed in the vegetative organs of Fragaria ananassa. The most prominent fluctuation was observed in the content of HHDPglucose, galloylquinic acid, ellagic acid pentoside, kaempferol glycoside, and ellagic acid in leaves, which increased in the morning and subsequently decreased in the evening and at night.

The infection of plants with phytopathogenic fungi is usually accompanied by an increase in the content of ellagic acid, which usually suggests the activation of oxidative processes in plant tissues. A significant increase in ellagic acid content observed $1 \mathrm{~h}$ after treatment with $0.4 \% \mathrm{LMC}$ suggests that it has a high elicitor activity and accelerates the hydrolysis of ellagotanins.

A high plant sensitivity was observed in the strawberry leaves $1 \mathrm{~h}$ after treatment with HMC, in terms of an increase by $22.0 \%$ in the content of kaempferol glycoside. In contrast, flavanol content decreased in leaves by 18.0\% after LMC treatment. This indicates differences in plant reactions and response to the treatment of chitosan solutions of different nature and molecular weights. The high speed and specificity of plant's physiological responses to chitosans of varying molecular weights indicate the existence of different ways of perception and transformation of the external molecular signals.

\section{References}

Atkinson N., Urwin P. (2012) The interaction of plant biotic and abiotic stresses: from genes to the field. J. Exp. Bot. 63(10): 3523-3543.

Babenko L.M., Smirnov O.E., Romanenko K.O., Trunova O.K., Kosakivska I.V. (2019) Phenolic compounds in plants. biogenesis and functions. Ukr. Biochem. J. 91(3): 5-18.

Barbehenn R., Jones C., Hagerman A., Karonen M., Salminen J. (2006) Ellagitannins have greater oxidative activities than condensed tannins and galloyl glucoses at high $\mathrm{pH}$ : potential impact on caterpillars. J. Chem. Ecol. 32: 2253-2267.
Bavaresco L., Zamboni M., Squeri C., Xu S., Abramowicz A., Lucini L. (2017) Chitosan and grape secondary metabolites: a proteomics and metabolomics approach. BIO Web of Conferences, 9, 01004, 40 ${ }^{\text {th }}$ World Congress of Vine and Wine.

Benhamou N., Nicole M. (1999) Cell biology of plant immunization against microbial infection: the potential of induced resistance in controlling plant diseases. Plant Physiol. Biochem. 37: 703-719.

Coqueiro D.S.O., de Souza A.A., Takita M.A., Rodrigues C.M., Kishi L.T., Machado L.A. (2015) Transcriptional profile of sweet orange in response to chitosan and salicylic acid. BMC Genom. 16(288): 1-14.

Coqueiro D.S.O., Maraschin M., Di Piero R.M. (2011) Chitosan reduces bacterial spot severity and acts in phenylpropanoid metabolism in tomato plants. J. Phytopathol. 159: 488-494.

Daudi A., Cheng Z., O'Brien J.A., Mammarella N., Khan S., Ausubel F.M., Bolwell G.P. (2012) The apoplastic oxidative burst peroxidase in arabidopsis is a major component of pattern-triggered immunity. Plant Cell. 24(1): 275-287.

Del Rio L.A., Lopez-Huertas E. (2016) ROS generation in peroxisomes and its role in cell signaling. Plant Cell Physiol. 57: 1364-1376.

Dmitriev A.P. (2002) Signal systems of plant immunity. Tsitologiia i Genetika (Cytol. Genet.) 36(3): 58-68.

Dmitriev A.P. (2003) Signal molecules for plant defense responses to biotic stress. Rus. J. Plant Physiol. 50(3): 417-425.

El Hadrami A., Adam L.R., El Hadrami I., Daayf F. (2010) Chitosan in plant protection. Marine Drugs. 8(4): 968-987.

Feduraev P., Chupakhina G., Maslennikov P., Tacenko N., Skrypnik L. (2019) Variation in phenolic compounds content and antioxidant activity of different plant organs from Rumex crispus L. and Rumex obtusifolius L. at different growth stages. Antioxidants 8: 237.

Hahn M.G. (1996) Microbial elicitors and their receptors in plants. Ann. Rev. Phytopathol. 34(1): 387-412.

Hanhineva K., Rogachev I., Kokko H., Mintz-Oron S., Venger I., Kärenlampi S., Aharoni A. (2008) Non-targeted analysis of spatial metabolite composition in strawberry (Fragaria $x$ ananassa) flowers. Phytochemistry 69(13): 2463-2481.

Hanhineva K., Soininen P., Anttonen M.J., Kokko H., Rogachev I., Aharoni A., Laatikainen R., Kärenlampi S. (2009) NMR and UPLC-qTOF-MS/MS characterisation of novel phenylethanol derivatives of phenylpropanoid glucosides from the leaves of strawberry (Fragaria $x$ ananassa $\mathrm{cv}$. Jonsok). Phytochem. Anal. 20: 353-364.

Helm R.F., Ranatunga T.D., Chandra M. (1997) Lignin-hydrolyzable tannin interactions in wood. J. Agric. Food Chem. 45: 3100-3106.

Hirano S., Nakahira T., Nakagawa M., Kim S.K. (1999) The preparation and applications of functional fibres from crab shell chitin. J. Biotechnol. 70: 373-377.

Inui H., Yamaguchi Y., Hirano S. (1997) Elicitor actions of $N$ acetylchitooligosaccharides and laminarioligosaccharides for chitinase and L-phenylalanine ammonia-lyase induction in rice suspension culture. Biosci. Biotech. Biochem. 61(6): 975-978. 
Kallio T., Kallio J., Jaakkola M., Mäki M., Kilpeläinen P., Virtanen V. (2013) Urolithins display both antioxidant and pro-oxidant activities depending on assay system and conditions. J. Agric. Food Chem. 61(45): 10720-10729.

Katiyar D., Hemantaranjan A., Singh B., Bhanu A. (2014) A future perspective in crop protection: chitosan and its oligosaccharides. Adv. Plants Agric. Res. 1: 1-8.

Khan W., Prithiviraj B., Smith D.L. (2003) Chitosan and chitin oligomers increase phenylalanine ammonia-lyase and tyrosine ammonia-lyase activities in soybean leaves. J. Plant Physiol. 160(8): 859-863.

Klessig D., Durner J., Noad R., Navarre D., Wendehenne D., Kumar D., Zhou J., Shah J., Zhang S., Kachroo P. et al. (2000) Nitric oxide and salicylic acid signaling in plant defense. Proc. Nat. Acad. Sci. 97: 8849-8855.

Klumpers J., Scalbert A., Janin G. (1994) Ellagitannins in European oak wood: polymerization during wood ageing. Phytochemistry 36(5): 1249-1252.

Köhle H., Young D.H., Kauss H. (1984) Physiological changes in suspension-cultured soybean cells elicited by treatment with chitosan. Plant Sci. Lett. 33: 221-230.

Kulikov S.N., Chirkov S.N., Il'ina A.V., Lopatin S.A., Varlamov V.P. (2006) Effect of the molecular weight of chitosan on its antiviral activity in plants. Prik. Biokhim. Mikrobiol. 42(2): 224-228.

Kulikov S.N., Varlamov V.P. (2008) The role of chitosan chemical structure in its elicitor activity. Uchen. Zapis. Kazansk. Univ. 150(2): 43-58.

Le Roy J., Huss B., Creach A., Hawkins S., Neutelings G. (2016) Glycosylation is a major regulator of phenylpropanoid availability and biological activity in plants. Front. Plant Sci. 7: 735.

Leister D. (2017) Piecing the puzzle together: the central role of reactive oxygen species and redox hubs in chloroplast retrograde signaling. Antioxid. Redox Signal. 30(9): 1206-1219.

Lopez-Moya F., Suarez-Fernandez M., Lopez-Llorca L.V. (2019) Molecular mechanisms of chitosan interactions with fungi and plants. Int. J. Mol. Sci. 20(332): 1-15.

Lucini L., Baccolo G., Rouphael Y., Colla G., Bavaresco L., Trevisan M. (2018) Chitosan treatment elicited defense mechanisms, pentacyclic triterpenoids and stilbene accumulation in grape (Vitis vinifera L.) bunches. Phytochemistry 156 : $1-8$.

Minibayeva F.V., Gordon L.K. (2003) Superoxide production and the activity of extracellular peroxidase in plant tissues under stress conditions. Russ. J. Plant Physiol. 50(3): 411-416.

Ozeretskovskaya O., Vasyukova N., Zinovieva S. (2002) Chitosan as an elicitor of induced plant resistance. [in:] Chitin and chitosan production, properties and usage. Ed. Skryabin G., Vikhoreva G., Varlamov V. Moscow. Nauka: 280-360.

Popova E.V., Domnina N.S., Kovalenko N.M., Borisova E.A., Kolesnikov L.E., Tyuterev S.L. (2017) Biological activity of chitosan with various molecular weights. Plant Protect. News 3(93): 28-33.
Povero G., Loreti E., Pucciariello C., Santaniello A., Di Tommaso D., Di Tommaso G., Kapetis D., Zolezzi F., Piaggesi A., Perata P. (2011) Transcript profiling of chitosantreated Arabidopsis seedlings. J. Plant Res. 124: 619-629.

Rane K., Hoover D. (1993) Production of chitosan by fungi. Food Biotech. 7(1): 11-33.

Salminen J.-P., Karonen M., Sinkkonen J. (2011) Chemical ecology of tannins: Recent developments in tannin chemistry reveal new structures and structure-activity patterns. Chem. Eur. J. 17: 2806-2816.

Schulenburg K., Feller A., Hoffmann T., Schecker J., Martens S., Schwab W. (2016) Formation of $\beta$-glucogallin, the precursor of ellagic acid in strawberry and raspberry. J. Exp. Bot. 67: 2299-2308.

Shittu H., Aisagbonhi E., Obiazikwor O. (2019) Plants' innate defence mechanisms against phytopathogens. J. Microbiol. Biotech. Food Sci. 9: 314-319.

Smirnova O.G., Kochetov A.V. (2015) Plant cell wall and the mechanisms of resistance to pathogens. Vavilov J. Gen. Breed. 19(6): 715-723.

Sokolov Y. (2014) Elicitors and their application. Proc. Nat. Acad. Sci. Belarus: Chem. Ser. 4: 109-118.

Subin O.V., Melnychuk M.D., Likhanov A.F., Spyrydonov V.G. (2018) Effect of chitosan of different origins on the contents of phenolic antioxidants in Fragaria ananassa Duch. leaves. Fiziol. Rast. Genet. 50(2): 124-133.

Tyuterev S.L. (2002) Scientific foundations of induced disease, resistance of plants. Saint-Petersburg.

Tyuterev S.L. (2015) Ecologically safe inducers of plant resistance to diseases and physiological stresses. Plant Protect. News 1(83): 3-13.

Vander P., Varum K.M., Domard A., Eddine El Gueddari N., Moerschbacher B.M. (1998) Comparison of the ability of partially $N$-acetylated chitosans and chitooligosaccharides to elicit resistance reactions in wheat leaves. Plant Physiol. 118(4): 1353-1359.

Volynets A.P. (2013) Phenolic compounds in plant life. Minsk: Belaruskaya navuka.

Waszczak C., Carmody M., Kangasjärvi J. (2018) Reactive oxygen species in plant signaling. Ann. Rev. Plant Biol. 69(1): 209-236.

Yordi E.G., Perez E.M., Matos M.J., Villares E.U (2012) Antioxidant and pro-oxidant effects of polyphenolic compounds and structure-activity relationship evidence. [in:] Nutrition, well-being and health. Ed. Bouayed J., Bohn T. InTechOpen: 23-48.

Zaprometov M.N. (1993) Phenolic compounds. Moscow: Nauka. 